\title{
ERRATUM
}

\section{Part VI \\ Science Teacher Education}

\author{
Ling L. Liang
}

(C) Springer Science+Business Media Dordrecht 2017

L.L. Liang et al. (eds.), Chinese Science Education in the 21st Century:

Policy, Practice, and Research, Contemporary Trends and Issues in Science

Education 45, DOI 10.1007/978-94-017-9864-8

\section{DOI 10.1007/978-94-017-9864-8_20}

In Table VI.1, the headings of the second and third columns were incorrectly interchanged in Part VI, page 374. The correct version as per Table VI.1 is left column being a China example and the right column being a US example.

The online version of the updated original Part can be found at http://dx.doi.org/10.1007/978-94-017-9864-8 


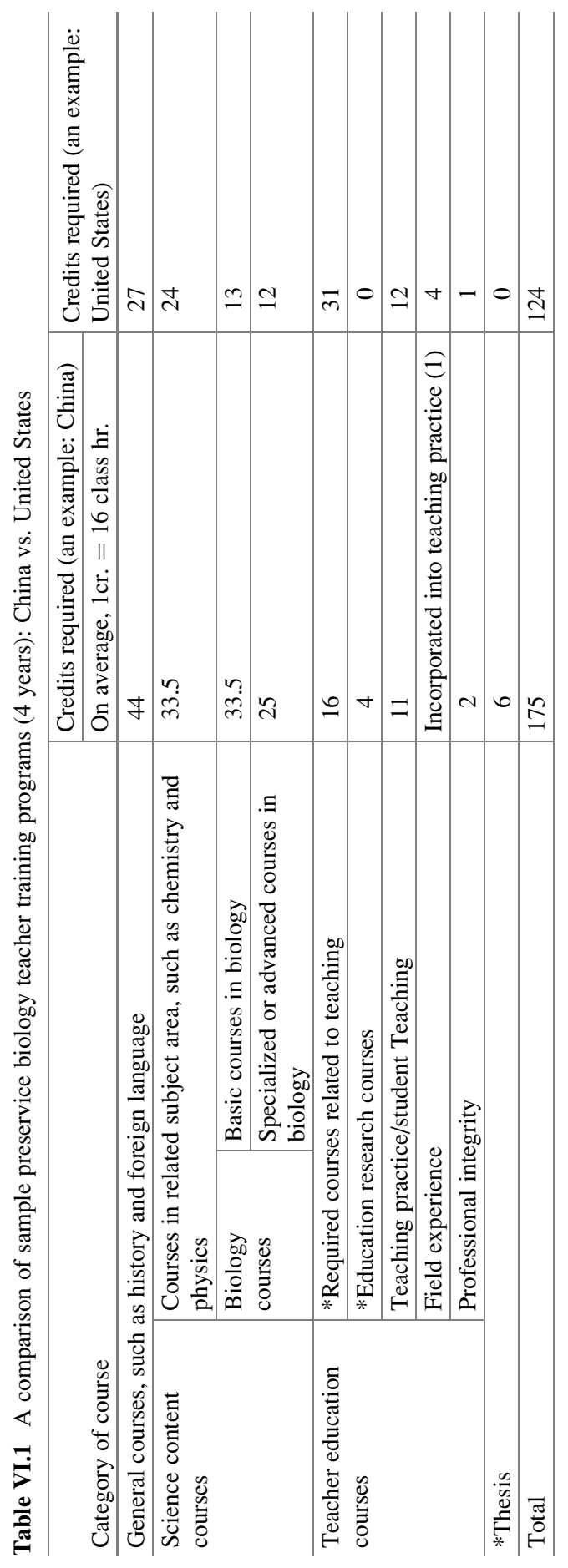

